1 Universidade Federal da Bahia (UFBA) - Salvador (BA), Brasil.

Orcid: https://orcid org/0000-0002-9285$194 \mathrm{X}$

anamariafsl@gmail.com

2 Universidade Federal da Bahia (UFBA) - Salvador (BA), Brasil.

Orcid: https://orcid org/0000-0002-14768649

sclchaves@gmail.com

${ }^{3}$ Universidade Federal da Bahia (UFBA) - Salvador (BA), Brasil.

Orcid: https://orcid. org/0000-0001-97506478

leticianrabelo@gmail.com

4 Universidade Federal da Bahia (UFBA) - Salvador (BA), Brasil.

Orcid: https://orcid org/0000-0002-6989-

7296

camila.odontoufba2@gmail. com

\section{Posicionamento das entidades odontológicas sobre a Política Nacional de Saúde Bucal, no período de $2015-2017$}

\author{
Positioning of dental entities on the National Oral Health Policy, in \\ the period 2015-2017
}

Ana Maria Freire de Lima Almeida1, Sônia Cristina Lima Chaves², Letícia Rabelo Nunes³, Camila

Oliveira Araújo 4

DOI: 10.1590/0103-11042018S207

RESUMO Este estudo analisou o posicionamento de entidades odontológicas nacionais sobre a Política Nacional de Saúde Bucal (PNSB), entre 2015 e 2017, no Brasil, como espaço de relações de força entre agentes e instituições. Foi realizada análise documental das publicações relacionadas sobre a política nos sites oficiais, em redes sociais e em notícias do Conselho Federal de Odontologia (CFO), da Associação Brasileira de Odontologia (ABO), das Federações de sindicatos e da Associação de Saúde Bucal Coletiva (Abrasbuco). O monitoramento foi semanal, segundo categorias: ações e posicionamento da entidade sobre a política, demandas profissionais e relações com o campo político. Observou-se, nesse período, que CFO e Federação Interestadual dos Odontologistas foram as entidades que mais publicaram sobre a política. As entidades sindicais e os representantes da Abrasbuco se posicionaram mais criticamente sobre as sucessivas mudanças na Coordenação Geral de Saúde Bucal em 2015. O fato que mobilizou todas as entidades, à exceção da $\mathrm{ABO}$, foi a possível extinção da coordenação, em 2016. Destaca-se o posicionamento comum das entidades pela defesa da expansão da política com novos postos de trabalho no SUS e articulação com o poder legislativo na aprovação de projetos de lei, como o da odontologia na Unidade de Tratamento Intensivo (UTI) e da transformação da PNSB em política de Estado.

PALAVRAS-CHAVE Política de saúde. Assistência odontológica. Odontologia. Saúde bucal.

ABSTRACT This study analyzed the positioning of national dental entities on the National Oral Health Policy (PNSB), between 2015 and 2017, in Brazil, as a space for relations of strength between agents and institutions. A documentary analysis of the related publications about politics was carried out on official websites, social networks and news from the Federal Council of Dentistry (CFO), of the Brazilian Association of Dentistry ( $A B O)$, the Federations of unions and the Association of Collective Oral Health (Abrasbuco). The monitoring was weekly, according to categories: actions and positioning of the entity on the politics, professional demands and relations with the political field. It was observed, during this period, that CFO and Interstate Odontologists Federation were the entities that most published about politics. The unions and representatives of Abrasbuco were more critically positioned about the successive changes in 
the General Coordination of Oral Health in 2015. The fact that mobilized all entities, with the exception of $A B O$, was the possible extinction of coordination, in 2016. It stands out the common position of entities for the defense of the expansion of the policy with new jobs in the SUS and articulation with the legislative power in the approval of bills, such as dentistry in the Intensive Care Unit (ICU) and the transformation of the PNSB into State politics.

KEYWORDS Health policy. Dental care. Dentistry. Oral health.

\section{Introdução}

A Constituição Brasileira, publicada em 1988, marcou a transição para o regime democrático no País e favoreceu o envolvimento dos diversos atores da sociedade nos processos de decisão e implementação das políticas sociais. Na política de saúde bucal, as entidades odontológicas historicamente protagonizam essa participação social e exerceram influência nos diferentes períodos de governo no período pós-constituinte, com destaque para o Conselho Federal de Odontologia (CFO) e para a Associação Brasileira de Odontologia (ABO) ${ }^{1}$. Rossi ${ }^{1}$ relata que, na década de 1980, essas entidades exerciam uma posição dominante no campo odontológico e marcaram seus posicionamentos na defesa dos interesses corporativos, mas sem uma preocupação explícita com as alternativas de enfrentamento dos problemas de saúde bucal da população brasileira, defendendo o modelo da odontologia de mercado, curativo e focado na atenção individual, mesmo no âmbito da prestação de serviços previdenciários.

Estudo de Soares e colaboradores ${ }^{2}$, que analisaram o posicionamento das entidades médicas quanto ao Sistema Único de Saúde (SUS), no período 2015-2016, de grande instabilidade política, apontou que as entidades médicas (Conselho Federal de Medicina, Associação Brasileira de Medicina e Federação Brasileira dos Médicos) foram fortes oponentes às políticas do governo federal antes do impeachment de Dilma Rousseff, como o Programa Mais Médicos, que contrariou os interesses da categoria médica, com forte caráter corporativo.

Contudo, não há estudos mais recentes sobre a atuação de agentes não governamentais na implementação da política de saúde bucal. Nesse espaço de luta, entre as entidades do campo odontológico, destacam-se atualmente, no cenário nacional, o $\mathrm{CFO}$, a $\mathrm{ABO}$, a Federação Nacional dos Odontologistas (FNO), a Federação Interestadual dos Odontologistas (FIO) e, na área da saúde coletiva, a Associação Brasileira de Saúde Bucal Coletiva (Abrasbuco). Todos esses atores estiveram presentes ao longo dos últimos anos nas Conferências Nacionais de Saúde, produzindo fatos políticos de mobilização pelos interesses dos Cirurgiões-Dentistas (CD), por um lado, e da assistência em saúde bucal como direito à saúde, por outro. Foram atuantes na luta para inclusão da saúde bucal no Programa Saúde da Família (PSF), que ocorreu no ano de 2000, e na reivindicação pela igualdade de proporção entre a equipe de saúde bucal e a equipe de saúde da família, e, posteriormente, em 2004, participaram do processo de construção e lançamento da Política Nacional de Saúde Bucal (PNSB Brasil Sorridente) ${ }^{3}$.

Silva, Jaccoud e Beghin ${ }^{4}$ destacam que, 
apesar de a sociedade ter avançado no exercício do acompanhamento, da participação e do controle das políticas públicas, há problemas envolvendo a mobilização dos setores representados, como a captura dos espaços participativos por interesses privados ou corporativos e a predominância do poder executivo nos processos decisórios. Compreender a forma como os diferentes agentes e instituições se posicionam e agem diante do processo histórico que envolve a resposta social a problemas de saúde é uma das principais atribuições da subárea da saúde coletiva denominada política, planejamento e gestão em saúde.

No caso da atenção à saúde bucal, chama a atenção a inexistência de estudos que analisem a participação e o posicionamento das entidades odontológicas com relação à política, aqui compreendida como a possibilidade de influência dos agentes e das instituições sobre o Estado, que é aquele que detém o monopólio da resposta social aos problemas evocados $^{5}$. Nesse sentido, este estudo busca analisar parte do espaço social da saúde bucal quanto ao posicionamento das entidades odontológicas a partir do acompanhamento e da sistematização dessa participação, realizado pelo eixo temático de Saúde Bucal do Observatório de Análise Política em Saúde (Oaps), do Instituto de Saúde Coletiva (ISC) da Universidade Federal da Bahia (UFBA), no período de 2015 a 2017.

\section{Material e métodos}

Este foi um estudo retrospectivo, descritivo, com abordagem qualitativa de monitoramento do posicionamento das entidades odontológicas, através da análise documental das publicações relacionadas com a Política Nacional de Saúde Bucal nos sites oficiais, redes sociais, documentos, cartas, atas, notícias, jornais e revistas das entidades monitoradas [Conselho Federal de Odontologia (CFO), Associação Brasileira de Odontologia (ABO), Federação Nacional dos Odontologistas (FNO), Federação Interestadual dos Odontologistas (FIO) e Associação Brasileira de Saúde Bucal Coletiva (Abrasbuco)], no período de 2015 a 2017.

A pesquisa foi exploratória no uso dos conceitos de espaço social e posição dos agentes através de suas instituições, oriundos da obra de Pierre Bourdieu ${ }^{5}$. Toda política se apresenta num determinado espaço social onde se estruturam as relações de força entre agentes e instituições, definidas em cada caso pelas posições diferenciadas que ocupam na distribuição de um tipo específico de capital, como dominantes ou dominados. Todo espaço de posições sociais se retraduz em um espaço de tomadas de posição, essa retradução se faz pela intermediação do espaço de disposições, ou seja, do habitus $^{6}$. No presente estudo, partiu-se do pressuposto de que há entidades dominantes no espaço de luta da saúde bucal que pautam a discussão e congregam as demais em torno de questões em jogo comuns, de interesse mútuo. E, entre elas, o CFO ocupa o polo dominante, por ter o metacapital do Estado ${ }^{5,6}$, seguido da $\mathrm{ABO}$, por apresentar a representação da odontologia 'liberal' e de mercado, que é dominante no habitus da classe.

Do ponto de vista da história, cabe destacar que o CFO e os Conselhos Regionais foram criados nos anos 1960 pela Lei ${ }^{\circ}$ 4.324, de 14 de abril de 1964. Os Conselhos são constituídos em seu conjunto em uma Autarquia, sendo cada um deles dotado de personalidade jurídica e de direito público, com autonomia administrativa e financeira e com a finalidade de supervisionar a ética profissional em toda a República ${ }^{7}$. A ABO Nacional foi fundada por volta de 1917 e é reconhecida como entidade de utilidade pública, sem fins lucrativos, dedicada à defesa da classe odontológica e da saúde oral da população brasileira. Está representada nas 27 unidades federativas através de Seções Estaduais e em 294 municípios, por meio de Regionais, no que é conhecida por 
Rede $\mathrm{ABO}^{8}$. A FNO foi fundada em 23 de fevereiro de 1948 pelos sindicatos do Ceará, Recife, Bahia, Paraná, Juiz de Fora, Niterói, Minas Gerais e Rio de Janeiro, e trata-se de uma entidade sindical que compreende todo território nacional, congregando sindicatos de Odontologia e representando legalmente os CD ${ }^{9}$. A FIO foi fundada em 1988 e congrega 21 Sindicatos de Odontologistas do País, e se considera uma instância superior que reúne o movimento sindical ${ }^{10}$. A criação da Abrasbuco ocorreu em agosto de 1998, em reunião paralela realizada durante o XIV Encontro Nacional de Administradores e Técnicos do Serviço Público Odontológico (Enatespo) e o III Congresso Brasileiro de Saúde Bucal, na cidade de Fortaleza, Ceará. Para seus organizadores, foi um episódio da luta e do desejo organizativo de pessoas que entendem a saúde bucal enquanto componente de qualidade de vida dos grupos sociais, direito de cidadania e responsabilidade do Estado, colocando-se no campo das políticas públicas ${ }^{11}$.

O monitoramento, compreendido como acompanhamento sistemático das publicações das referidas entidades, foi semanal, e o material coletado foi distribuído nas categorias de análise: ações e posicionamento da entidade sobre a política, demandas profissionais, relações com o campo político, relações com o poder executivo e relações entre entidades. A distribuição dos achados nessas categorias foi realizada por dois pesquisadores, separadamente, e não houve discordâncias entre eles. Foi também realizada uma síntese descritiva das principais ações e posicionamentos por ano (quadro 1), e, a partir das categorias de análise propostas, foi construída uma síntese dos principais posicionamentos das entidades odontológicas, no período de 2015 a 2017 (quadro 2).

Quadro 1. Síntese das informações encontradas nas publicações das entidades odontológicas ${ }^{\star}$ por categorias de análise, no período de 2015 a 2017

\begin{tabular}{|c|c|c|c|}
\hline \multirow[t]{2}{*}{ Categorias de Análise } & \multicolumn{3}{|c|}{ Ano } \\
\hline & 2015 & 2016 & 2017 \\
\hline $\begin{array}{l}\text { Ac̣ões e Posicionamentos sobre a Política } \\
\text { Defesa do SUS, expansão, valorização e melhorias dos servi- } \\
\text { ços públicos odontológicos }\end{array}$ & $\begin{array}{l}\text { CFO, ABO, FNO, } \\
\text { FIO, ABRAS- } \\
\text { BUCO }\end{array}$ & $\begin{array}{l}\text { CFO, ABO, FNO, } \\
\text { FIO, ABRAS- } \\
\text { BUCO }\end{array}$ & $\begin{array}{l}\text { CFO, ABO, FNO, } \\
\text { FIO, ABRAS- } \\
\text { BUCO }\end{array}$ \\
\hline $\begin{array}{l}\text { Defesa da política de fluoretação das águas de abastecimento } \\
\text { público }\end{array}$ & $\mathrm{CFO}, \mathrm{ABO}$ & - & - \\
\hline $\begin{array}{l}\text { Organização de eventos, atos, espaços, comissões e/ou fren- } \\
\text { tes para discussão do SUS e/ou da PNSB }\end{array}$ & $\mathrm{FNO}, \mathrm{FIO}$ & - & - \\
\hline Defesa de plano de carreira no SUS & FNO & - & - \\
\hline $\begin{array}{l}\text { Posicionamento contrário sobre as mudanças na Coordenação } \\
\text { Nacional de Saúde Bucal do MS }\end{array}$ & $\begin{array}{l}\text { CFO, FNO, FIO, } \\
\text { ABRASBUCO }\end{array}$ & $\begin{array}{l}\text { CFO, FNO, FIO, } \\
\text { ABRASBUCO }\end{array}$ & - \\
\hline $\begin{array}{l}\text { Apoio ao projeto de lei que transforma a PNSB Brasil Sorriden- } \\
\text { te em política de Estado. }\end{array}$ & - & $\mathrm{CFO}, \mathrm{FIO}, \mathrm{ABO}$ & $\begin{array}{l}\mathrm{CFO}, \mathrm{FIO}, \mathrm{ABO} \\
\mathrm{FNO}\end{array}$ \\
\hline $\begin{array}{l}\text { Demandas Profissionais } \\
\text { Defesa de plano de carreira no SUS }\end{array}$ & FNO & FNO & - \\
\hline $\begin{array}{l}\text { Autoria e/ou defesa de Projetos de Lei de interesse da classe } \\
\text { odontológica }\end{array}$ & $\mathrm{CFO}, \mathrm{ABO}, \mathrm{FNO}$ & CFO & $\mathrm{CFO}, \mathrm{ABO}, \mathrm{FNO}$ \\
\hline Aumento do número de vagas para CD do SUS & - & $\mathrm{CFO}, \mathrm{FNO}, \mathrm{FIO}$ & - \\
\hline $\begin{array}{l}\text { Relações com o campo político } \\
\text { Apoio e publicação sobre parlamentares }\end{array}$ & $\mathrm{FNO}, \mathrm{CFO}$ & - & - \\
\hline
\end{tabular}


Quadro 1. (cont.)

Relações com o poder executivo

CFO

CFO

CFO

Publicações de apoio ou divulgação de ações da Coordenação

Nacional de Saúde Bucal do MS

\section{Relações entre entidades odontológicas}

$\mathrm{CFO}, \mathrm{ABO}, \mathrm{FNO} \quad \mathrm{CFO}, \mathrm{FIO}, \mathrm{FNO} \quad \mathrm{ABO}, \mathrm{CFO}, \mathrm{FNO}$

Participação em eventos e espaços com as demais entidades

odontológicas com temas relacionados ao SUS e/ou à PNSB

Fonte: Elaboração própria, com base no material coletado.

*Conselho Federal de Odontologia (CFO), Associação Brasileira de Odontologia (ABO), Federação Nacional dos Odontologistas (FNO), Federação Interestadual dos Odontologistas (FIO) e a Associação Brasileira de Saúde Bucal Coletiva (Abrasbuco).

Quadro 2. Principais ações e posicionamento das entidades odontológicas* interessadas na PNSB no período de 2015 a 2017

\begin{tabular}{l}
\hline 2015 \\
\hline O CFO se posiciona como 'parceiro' do \\
Ministério da Saúde (MS) e afirmou pre- \\
ocupação com a ampliação dos serviços \\
públicos de saúde bucal. Reforçou deman- \\
das da classe odontológica presentes no \\
documento 'O que esperamos do próximo \\
presidente do Brasil', como a ampliação \\
dos sistemas de fluoretação das águas de \\
abastecimento público e da política Brasil \\
Sorridente Indígena.
\end{tabular}

Diversas entidades (ABO, CFO, FIO e FNO Abeno, ABCD) entregaram carta ao ministro da saúde, solicitando a manutenção da PNSB e da então coordenadora geral de Saúde Bucal, Rozângela Camapum, ex-presidente da $\mathrm{FIO}$, que ocupou o cargo por cerca de dois meses, sendo substituída por Ademir Fatric, empresário ligado a planos odontológicos.

A FIO criticou a exoneração de Rozângela publicando o texto 'Para onde vai o Brasil Sorridente: SUS ou mercado?'.

A ABRASBUCO também foi contrária à saída da coordenadora e destacou o envio do documento 'Carta a Presidente Dilma Rousseff e à sociedade - Nota Pública Sobre o SUS e a Agenda Brasil'. As entidades criticam o documento 'Agenda Brasil' por ameaçar o caráter universal do SUS. Assinaram essa carta a Abrasco, Abres; Ampasa; APSP; Cebes; Idisa e Rede Unida - SBB.

\section{6}

O CFO destacou o papel da Comissão Parlamentar da entidade na aprovação pelo Senado do PL 34/2013, que regulamenta a presença do cirurgião-dentista nas UTIs e inclui a assistência odontológica no atendimento e na internação domiciliares do SUS.

Em julho, as entidades emitiram notas e comunicados de repúdio (CFO, FIO, FNO, Conselhos Regionais - BA, SP, SE, PR, RS, MT; Sindicatos - Soergs, Soepar, Sinodonto-SE, SoDF) sobre a possível extinção da Coordenação Nacional de Saúde Bucal (CNSB). Em agosto, foi nomeada para o cargo de coordenadora Patrícia Ferraz, onde permaneceu apenas por cinco meses.

Em dezembro, a FIO, FNO e CFO organizaram uma Assembleia Conjunta com os presidentes dos CROs, com o objetivo de somar as forças do Sistema $\mathrm{CFO} / \mathrm{CRO}$ s e entidades sindicais em prol das causas da categoria odontológica. Nesse encontro, a FNO destacou como pleito o aumento do número de vagas para cirurgiões-dentistas no SUS.

\section{7}

O CFO e a $\mathrm{ABO}$ destacaram a realização do XXXV Ciosp, evento de repercussão nacional onde a discussão da PNSB vem sendo mantida.

A FIO deu grande enfoque a questões sobre as reformas da previdência social e trabalhista. A terceirização na saúde também foi tema de debate. A FNO encaminhou ofício ao presidente da Câmara dos Deputados, Rodrigo Maia (DEM/RJ), solicitando a preservação da aposentadoria especial dos Cirurgiões-Dentistas.

A FNO manifestou-se contra a proposta de criação do plano de saúde popular que foi encaminhada à Agência Nacional de Saúde (ANS) pelo MS. A entidade também se mobilizou contra a reforma da Previdência.

$A B O$ publicou inúmeras postagens em sua página no Facebook a respeito do PL que torna a política Brasil Sorridente uma lei federal.

Em julho, houve um anúncio de liberação de R\$344,3 milhões para a saúde bucal, realizado no Planalto, em Brasília, com participação do CFO. A FIO e FNO publicam sobre esse assunto em seus sites oficiais.

Em agosto, o CFO, ABO, FIO, FNO, Abrasco, Cebes e membros da Abrasbuco manifestaram contrariedade sobre a revisão da Política Nacional de Atenção Básica (PNAB). 
Quadro 2. (cont.)

\begin{tabular}{|c|c|c|}
\hline $\begin{array}{l}\text { Destaca-se a participação do CFO e ABO } \\
\text { no Congresso Internacional de Odonto- } \\
\text { logia de São Paulo (Ciosp) e na mesa de } \\
\text { abertura do Encontro de Coordenadores de } \\
\text { Saúde Bucal do Sistema Público; da FNO } \\
\text { nos debates das etapas municipais, esta- } \\
\text { duais e nacional da XV CNS, realizadas no } \\
\text { final de } 2015 \text {, em Brasília/DF; e da FIO, na } \\
\text { construção do IX Congresso da Federação } \\
\text { Interestadual dos Odontologistas (Confio), } \\
\text { cujo tema foi 'O mercado de trabalho na } \\
\text { Odontologia: desafio atual público e pri- }\end{array}$ & $\begin{array}{l}\text { O CFO, a FIO, ABO e o ex- } \\
\text {-coordenador de Saúde Bucal, } \\
\text { Gilberto Pucca, manifestaram } \\
\text { apoio ao projeto de lei do sena- } \\
\text { dor Humberto Costa (PT-PE) } \\
\text { e do deputado Jorge Solla (PT- } \\
\text {-BA), para transformar o progra- } \\
\text { ma Brasil Sorridente em política } \\
\text { de Estado. }\end{array}$ & $\begin{array}{l}\text { Em outubro, O CFO discutiu sobre } \\
\text { a criação da Frente Parlamentar da } \\
\text { Odontologia, encabeçada pelo presi- } \\
\text { dente da entidade, Juliano do Vale, no } \\
\text { intuito de defender os interesses da } \\
\text { classe profissional. } \\
\text { No dia } 5 \text { de outubro, a FNO participou } \\
\text { de uma reunião do Conselho Nacional } \\
\text { de Saúde, junto ao Ministro da Saúde, } \\
\text { Ricardo Barros, onde foi requerida a } \\
\text { revogação da portaria da Nova PNAB. }\end{array}$ \\
\hline
\end{tabular}

*Conselho Federal de Odontologia (CFO), Associação Brasileira de Odontologia (ABO), Federação Nacional dos Odontologistas (FNO), Federação Interestadual dos Odontologistas (FIO) e a Associação Brasileira de Saúde Bucal Coletiva (Abrasbuco).

As categorias de análise foram assim denominadas: a) ações e posicionamento da entidade sobre a política - por exemplo, comentários e opiniões do presidente da entidade no editorial dos jornais; b) demandas profissionais, como solicitações específicas dos profissionais (CD, TSB e ASB) - por exemplo, aumento de postos de trabalho, salários, carga horária, plano de carreira no SUS, capacitação profissional; c) relações com o campo político, encontros, reuniões e entrevistas com os políticos - isso pode estar expresso nas entrevistas de deputados e vereadores e em reuniões de trabalho; d) relações com o poder executivo, como encontros, reuniões, entrevistas e espaço nas publicações da entidade com os atores do governo; e e) relações entre entidades: encontros, reuniões e entrevistas entre as entidades.

\section{Resultados}

O Posicionamento sobre a Política apontou que as entidades publicaram, em algum momento do período monitorado, sobre a defesa do SUS, expansão e valorização e melhorias dos serviços públicos odontológicos, bem como posicionamento contrário sobre as mudanças realizadas na Coordenação Geral de Saúde Bucal (CGSB) do Ministério da
Saúde (MS) e apoio ao projeto de lei de 2016, que busca transformar a Política Nacional de Saúde Bucal (PNSB) em política de Estado. A defesa da política de fluoretação das águas de abastecimento público foi destacada pela $\mathrm{ABO}$, pelo $\mathrm{CFO}$ e pela Abrasbuco. A organização de eventos, atos, espaços, comissões e/ou frentes para discussão do SUS e/ou da PNSB e a defesa de plano de carreira no SUS foram protagonizadas pelas entidades sindicais (FNO e FIO). As Demandas Profissionais foram frequentes nos posicionamentos do CFO, da FNO e da FIO na defesa de plano de carreira no SUS, autoria e/ou defesa de Projetos de Lei de interesse da classe odontológica e solicitação de aumento do número de vagas para CD no SUS.

Quanto às relações com o campo político, as publicações do CFO e da FNO apontam para o apoio a Projetos de Lei (PL) de interesse da odontologia e/ou defendem a política de saúde bucal (quadro 3). Nas Relações com o poder executivo, o principal achado foram publicações do CFO de apoio ou divulgação de ações da CGSB do MS. E, por fim, nas relações entre entidades foram encontradas diversas notícias de todas as organizações monitoradas sobre a participação em eventos e espaços com as demais entidades odontológicas com temas relacionados ao SUS e à PNSB. 
Quadro 3. Projetos de Lei das demandas profissionais da odontologia brasileira, 2003 a 2017

\begin{tabular}{|c|c|c|c|}
\hline Projeto de Lei (PL)/Ano & Autor/Partido & Assunto & Situação atual \\
\hline PL 957/03 & Deputado Vanderlei Assis (PPSP) & $\begin{array}{l}\text { Regulamenta a Odontologia do Trabalho - dis- } \\
\text { põe sobre a especialização em Odontologia do } \\
\text { Trabalho Comissão de Legislação Participativa. }\end{array}$ & $\begin{array}{l}\text { Aguardando Designação de Relator } \\
\text { na Comissão de Constituição e } \\
\text { Justiça e de Cidadania (CCJC) } \\
\text { 19/03/2015 - Mesa Diretora da } \\
\text { Câmara dos Deputados (Mesa) }\end{array}$ \\
\hline PL 1140/03 & Deputado Rubens Otoni (PT/GO). & $\begin{array}{l}\text { Regulamenta as profissões de técnico em hi- } \\
\text { giene dental e auxiliar de consultório dentário }\end{array}$ & $\begin{array}{l}\text { Transformado na Lei Ordinária } \\
\text { 11889/2008 }\end{array}$ \\
\hline PL 1823/03 & $\begin{array}{l}\text { Deputado Geraldo Resende (PPS/ } \\
\text { MS) }\end{array}$ & $\begin{array}{l}\text { Proíbe a criação de novos cursos de Odontolo- } \\
\text { gia e a ampliação de vagas nos cursos existen- } \\
\text { tes e dá outras providências. }\end{array}$ & $\begin{array}{l}\text { 11/02/2015: Mesa Diretora da } \\
\text { Câmara dos Deputados (Mesa) }\end{array}$ \\
\hline PL 3466/04 & $\begin{array}{l}\text { Deputado Inocêncio Oliveira (PFL/ } \\
\text { PE) }\end{array}$ & $\begin{array}{l}\text { Estabelece critérios para a edição da lista } \\
\text { referencial de honorários médicos no âmbito } \\
\text { nacional e dá outras providências. }\end{array}$ & $\begin{array}{l}\text { 05/06/2007 - Aguardando Apre- } \\
\text { ciação pelo Senado Federal }\end{array}$ \\
\hline PL 3520/04 & Deputado Vanderlei Assis (PP/TO) & $\begin{array}{l}\text { Altera o art. 162, Seção III, e o art. 168, Seção } \\
\text { V, do Capítulo V do Titulo II da Consolidação } \\
\text { das Leis do Trabalho, relativo à segurança e } \\
\text { medicina do trabalho e dá outras providências, } \\
\text { obrigando as empresas a manter serviços } \\
\text { especializados em segurança em medicina e } \\
\text { odontologia do trabalho. }\end{array}$ & Arquivado \\
\hline PL 422/2007 & $\begin{array}{l}\text { Deputado Flaviano Melo (PMDB/ } \\
\text { AC) }\end{array}$ & $\begin{array}{l}\text { Odontologia do Trabalho - altera o art. 162, } \\
\text { Seção III, e o art. 168, Seção V, do Capítulo } \\
\text { V do Título II da Consolidação das Leis do } \\
\text { Trabalho, relativo à segurança e medicina do } \\
\text { trabalho e dá outras providências. }\end{array}$ & $\begin{array}{l}\text { 24/03/2015 - Enviado à Comis- } \\
\text { são de Constituição e Justiça e de } \\
\text { Cidadania (CCJC) }\end{array}$ \\
\hline PL 3.734/2008 & $\begin{array}{l}\text { Deputado Ribamar Alves (PSB/ } \\
\text { MA) }\end{array}$ & $\begin{array}{l}\text { Piso Salarial - Altera a Lei } 3.999 \text {, de } 15 \text { de } \\
\text { dezembro de } 1961 \text {, que altera o salário mínimo } \\
\text { dos médicos e cirurgiões-dentistas. Fixa em } \\
\text { R } \$ 7 \text { mil o salário mínimo dos médicos, sendo } \\
\text { o valor horário de } R \$ 31,81 \text {. }\end{array}$ & Arquivado \\
\hline PEC 362/2009 & Deputado Maurício Rands (PT/PE) & $\begin{array}{l}\text { Dispõe sobre planos de carreira do Sistema } \\
\text { Único de Saúde e dá outras providências, por } \\
\text { meio de acréscimo de parágrafos ao art. } 198 \\
\text { da Constituição Federal. }\end{array}$ & Arquivado. \\
\hline PL 140/2009 & $\begin{array}{l}\text { Senador Gilvam Borges (PMDB/ } \\
\text { AP) }\end{array}$ & $\begin{array}{l}\text { Piso salarial - altera dispositivos da Lei } 3.999 \text {, } \\
\text { de } 15 \text { de dezembro de 1961, para fixar o valor } \\
\text { do piso salarial e a jornada de trabalho dos } \\
\text { médicos e cirurgiões-dentistas, e dá outras } \\
\text { providências. O piso salarial é fixado em } R \$ \\
7.000,00 \text { (sete mil reais) mensais. }\end{array}$ & $\begin{array}{l}\text { Situação: projeto está pronto para } \\
\text { votação em plenário. Aguarda } \\
\text { inclusão em pauta. }\end{array}$ \\
\hline $\begin{array}{l}\text { PL 555/2010 - anexado } \\
\text { ao PL472/2009 PL } \\
147 / 2012\end{array}$ & Arnaldo Faria de Sá (PTB/SP) & $\begin{array}{l}\text { Regulamenta o inciso III do } \$ \text { 4 do art. } 40 \text { da } \\
\text { Constituição, que dispõe sobre a concessão } \\
\text { de aposentadoria especial ao servidor público } \\
\text { titular de cargo efetivo cujas atividades sejam } \\
\text { exercidas sob condições especiais que preju- } \\
\text { diquem a saúde ou a integridade física. }\end{array}$ & $\begin{array}{l}\text { 20/09/2017 - Comissão de Seguri- } \\
\text { dade Social e Família (CSSF) } \\
\text { Retirado de pauta a requerimento } \\
\text { da deputada Carmen Zanotto. }\end{array}$ \\
\hline PEC 74/2011 & $\begin{array}{l}\text { Deputado Mendonça Prado (DEM/ } \\
\text { SE) }\end{array}$ & $\begin{array}{l}\text { Acrescenta o art. 197-A no Título VIII, Capítu- } \\
\text { lo II, Seção II - "Da Saúde", da Constituição da } \\
\text { República Federativa do Brasil de 1988, crian- } \\
\text { do a carreira de Cirurgião-Dentista de Estado. }\end{array}$ & Arquivada \\
\hline
\end{tabular}


Quadro 3. (cont.)

\begin{tabular}{|c|c|c|c|}
\hline PL 1187/2011 & Deputada Gorete Pereira (PR/CE) & $\begin{array}{l}\text { Técnico em Saúde Bucal (TSB) e de Auxiliar } \\
\text { em Saúde Bucal (ASB) - altera a Lei no } 11.889 \text {, } \\
\text { de } 24 \text { de dezembro de 2008, que regulamenta } \\
\text { o exercício das profissões de Técnico em Saú- } \\
\text { de Bucal e de Auxiliar em Saúde Bucal, para } \\
\text { instituir piso salarial profissional nacional. }\end{array}$ & $\begin{array}{l}\text { 01/12/2015 - Mesa Diretora da } \\
\text { Câmara dos Deputados (MESA) } \\
\text { Aguardando Designação de Relator } \\
\text { na Comissão de Seguridade Social } \\
\text { e Família (CSSF) }\end{array}$ \\
\hline PL 2.750/11 & Deputado Andre Moura (PSC/SE) & $\begin{array}{l}\text { Fixa o piso salarial dos Cirurgiões-Dentistas e } \\
\text { médicos em R } \$ 10.125,82 \text { e passa a ser corri- } \\
\text { gido a cada } 12 \text { meses segundo o INPC, válido } \\
\text { para profissionais da rede pública e privada. }\end{array}$ & $\begin{array}{l}\text { O Projeto encontra-se na Comis- } \\
\text { são de Seguridade Social e Família } \\
\text { (CSSF) da Câmara dos Deputados } \\
\text { e aguarda a designação de Relator. }\end{array}$ \\
\hline $\begin{array}{l}P L 34 / 2013 \mathrm{PL} \\
2.776 / 2008\end{array}$ & Deputado Neilton Mulim (PR/RJ) & $\begin{array}{l}\text { Inclusão do dentista na UTIS: Estabelece a } \\
\text { obrigatoriedade da presença de profissionais } \\
\text { de odontologia nas unidades de terapia inten- } \\
\text { siva e dá outras providências. }\end{array}$ & $\begin{array}{l}\text { Último local: 05/05/2016 - Secre- } \\
\text { taria Legislativa do Senado Federal } \\
\text { Último estado: 05/05/2016 - } \\
\text { Pronto para deliberação do plenário }\end{array}$ \\
\hline PL 5728/2013 - & Deputado Benjamin Maranhão & Dispõe sobre o Plano Nacional de Carreiras, & Arquivado \\
\hline
\end{tabular}

PNCCS-SUS (PMDB/PB) Cargos e Salários dos profissionais de saúde do Sistema Único de Saúde (SUS) - PNCCS-SUS.

PLC 86/2014 Deputado Dr. Grilo (PLS/MG)

Institui a Semana Nacional de Prevenção do Câncer Bucal.

PL 316/2014 Senador Paulo Davim (PV/RN)

Altera a Lei no 3.999, de 15 de dezembro de 1961, para fixar o piso salarial dos médicos e cirurgiões-dentistas e excluir do âmbito de aplicação da lei os auxiliares laboratorista e radiologista.

PL 765/2015 Benjamin Maranhão (SD/PB)

Altera a lei no 3.999, de 15 de dezembro de 1961, que altera o salário mínimo dos médicos e cirurgiões-dentistas.

Altera a Lei no 8.080, de 19 de setembro de 1990, para estabelecer parâmetros aplicáveis à gestão de recursos humanos no âmbito de instituições integradas ao Sistema Único de Saúde (SUS), e dá outras providências.

Prevê a alteração da Lei 8.080, de 19 de setembro de 1990, para incluir a saúde bucal no campo de atuação do SUS.
Sancionado e transformado na Lei no 13.230 , de 28 de dezembro de 2015.

Relator atual: Garibaldi Alves Filho Último local: 28/06/2017 - Comissão de Assuntos Econômicos (Secretaria de Apoio à Comissão de Assuntos Econômicos)

Apensados PL 776/2015 PL 1602/2015

Aguardando Parecer do Relator na Comissão de Seguridade Social e Família (CSSF), na Câmara dos Deputados

Aguardando Deliberação do Recurso na Mesa Diretora da Câmara dos Deputados (MESA)

Aprovada por Comissão em decisão terminativa

Destino: 01/08/2017 - Remetida a Câmara dos Deputados

Fonte: Elaboração própria, com base no material coletado. 


\section{Ações e posicionamentos das enti- dades relacionadas com a PNSB, em 2015}

No ano de 2015, o CFO, a ABO e a FNO manifestaram atuação junto ao Congresso Nacional para aprovação de PL de interesse para a classe odontológica, entre eles, o PL que trata da obrigatoriedade de um CD nas Unidades de Terapia Intensiva (UTIs), no âmbito hospitalar das redes pública e privada ${ }^{7-9}$. Os projetos de lei citados nas publicações monitoradas estão sistematizados no quadro 3.

Em suas publicações, foi frequente o posicionamento do $\mathrm{CFO}$ e da $\mathrm{ABO}$ como entidades 'parceiras' do MS na implantação das políticas públicas de saúde bucal. O CFO publicou dados da Pesquisa Nacional de Saúde do Instituto Brasileiro de Geografia e Estatística (IBGE), realizada em 2013, e defendeu a priorização de programas que ampliem os serviços públicos de saúde bucal, considerando o dado da pesquisa que indica que $74,3 \%$ das pessoas buscam serviços odontológicos em consultório ou clínicas particulares. O sistema de fluoretação das águas de abastecimento público também esteve presente nas publicações do $\mathrm{CFO}$ e da ABO, no ano de 2015. O CFO solicitou ampliação do investimento na fluoretação e da política do Brasil Sorridente Indígena no documento 'O que esperamos do próximo presidente do Brasil'’12.

As entidades participaram de diversos eventos no País, com destaque para o CFO. A autarquia participou da abertura do IV Encontro Sul Brasileiro de Saúde Bucal, na cidade de Campo Grande (MS), que teve como tema 'Desafios e Perspectivas da Saúde Bucal Coletiva'13. Participou, também, da V Reunião de Pesquisa em Saúde Bucal Coletiva, em Natal, RN, a qual reuniu pesquisadores e profissionais da área, bem como representantes de entidades odontológicas e a então coordenadora de Saúde Bucal do MS, Rozângela Camapum ${ }^{\mathbf{1 4}}$.

Um fato marcante no ano de 2015 foi a nomeação da CD Rozângela Fernandes Camapum, ex-presidente da Federação Interestadual de Odontologia, para o cargo de coordenadora da CGSB do $\mathrm{MS}^{15}$. Esse cargo havia sido ocupado por Gilberto Alfredo Pucca-Junior, CD, sanitarista, desde a implantação da PNSB, a partir de 2003. Rozângela Camapum foi exonerada do cargo após dois meses, em 17 de novembro de 2015, sendo substituída por Ademir Fatric, empresário ligado a planos odontológicos. A saída de Rozângela motivou entidades odontológicas Nacionais - Associação Brasileira de Ensino Odontológico (Abeno), Associação Brasileira de Cirurgiões-dentistas (ABCD), ABO Nacional, CFO, FIO e FNO - a entregar carta ao ministro da saúde, Marcelo Castro, solicitando a manutenção da Política Nacional de Saúde Bucal e da então coordenadora, para evitar quaisquer rupturas nas ações desenvolvidas na área pelo MS. Ainda em novembro de 2015, a FIO publicou um texto intitulado 'Para onde vai o Brasil Sorridente: SUS ou mercado?', no qual criticou a inesperada exoneração da coordenadora, ressaltando sua carreira sindical e na gestão, além de questionar o futuro da política de saúde bucal diante da entrada de um novo coordenador ligado ao mercado de planos odontológicos privados ${ }^{16}$. A Abrasbuco também se manifestou contra a mudança da Coordenação Nacional de Saúde Bucal e encaminhou um ofício ao MS no dia 22 de novembro, solicitando uma audiência para discutir o assunto. A entidade reafirmou o compromisso com o SUS e demais políticas inseridas nele e publicou no documento a seguinte afirmação: "jamais concordaremos com medidas que tenham direção contrária o que claramente representaria retrocessos inaceitáveis"17.

Em 2015, a FNO elaborou propostas para compor os debates das etapas municipais, estaduais e nacional da XV Conferência Nacional de Saúde, realizada 
no final de 2015, em Brasília (DF). Entre as propostas para a Atenção Básica, estavam a ampliação das equipes de saúde bucal na Estratégia de Saúde da Família (ESF) e das equipes ribeirinhas e a ampliação da atenção básica para o terceiro turno. Já na média complexidade, indicou ampliação dos laboratórios de prótese dentária, criação e implantação de centros de imagem e a garantia de acesso para os brasileiros de todas as especialidades de Odontologia. $\mathrm{Na}$ área de recursos humanos, a entidade pautou a aprovação do piso nacional e da carreira única para todos os trabalhadores do SUS ${ }^{18}$.

Destaca-se, também, a participação da FIO na LXX Reunião Ordinária da Mesa Nacional de Negociação Permanente do SUS (MNNP-SUS), da qual faz parte, em Brasília. Esse encontro elaborou documento para a XV Conferência Nacional de Saúde (CNS), com propostas sobre a valorização do trabalho e da educação no âmbito do SUS e discussão das diretrizes da Agenda Nacional do Trabalho Decente para Trabalhadores e Trabalhadoras do SUS (ANTD-SUS) ${ }^{19}$.

A Abrasbuco publicou o envio de documento intitulado 'Carta à Presidente Dilma Rousseff e à sociedade - Nota Pública Sobre o SUS e a Agenda Brasil', o qual criticava o documento 'Agenda Brasil', apresentado por lideranças do Senado ao Governo Federal, em agosto de 2015, com a proposta de extinção do SUS universal e cobrança de cidadãos assistidos pela rede pública de saúde, de acordo com a faixa de renda. Assinaram essa carta a Associação Brasileira de Saúde Coletiva (Abrasco); Associação Brasileira de Economia da Saúde (Abres); Associação Nacional do Ministério Público de Defesa da Saúde (Ampasa); Associação Paulista de Saúde Pública (APSP); Centro Brasileiro de Estudos de Saúde (Cebes); Instituto de Direito Sanitário Aplicado (Idisa) e Rede Unida Sociedade Brasileira de Bioética $(\mathrm{SBB})^{20}$.

\section{Ações e posicionamentos das enti- dades relacionadas com a PNSB, em 2016}

No início de 2016, o CFO trouxe o papel da Comissão Parlamentar da entidade na aprovação, pela Comissão de Assuntos Sociais do Senado, do Projeto de Lei $\mathrm{n}^{\circ} 34 / 2013$, que regulamenta a presença do CD nas UTIs e inclui a assistência odontológica no atendimento e na internação domiciliares do SUS (quadro 3). Em maio de 2016, o Conselho recebeu a visita do então Coordenador Geral de Saúde Bucal do MS, Ademir Fratric Bacic, e o presidente do CFO, à época, Ailton Morilhas, manteve em seu discurso o estabelecimento de parceria da entidade com o MS:

Esse é o objetivo do CFO, trabalhar em conjunto com o os CROs e com a Coordenação de Saúde Bucal do Ministério da Saúde para que possamos, efetivamente, beneficiar o cidadão brasileiro, [afirmou Morilhas] ${ }^{21}$.

A instabilidade política no Brasil, presente no cenário de 2015, permaneceu e se agravou em 2016. No mês de julho, foram exonerados 73 cargos comissionados do MS, incluindo o coordenador, Ademir Fatric, que havia assumido em novembro de 2015. Essa nova mudança na coordenação gerou especulações sobre uma possível extinção da Coordenação Nacional de Saúde Bucal. Esses fatos movimentaram as entidades odontológicas, que emitiram em suas redes sociais notas e comunicados de repúdio e preocupação (CFO²2; Conselhos Regionais - BA, SP, SE, PR, RS, MT; Sindicatos - Soergs, Soepar, Sinodonto-SE, SODF; FIO ${ }^{23}, \mathrm{FNO}^{24}$ ). A FIO destacou em sua nota de repúdio que a extinção da coordenação nacional implicaria redução ainda maior dos investimentos da saúde bucal no SUS e, consequentemente, perda dos avanços conquistados nos 14 anos de existência do Brasil Sorridente ${ }^{23}$. Não foi encontrada manifestação pública sobre essa possível extinção da coordenação nacional por parte da $\mathrm{ABO}$. 
Mais uma vez a Federação Interestadual dos Odontologistas é obrigada a vir a público externar completo repúdio contra ameaças do Ministério da Saúde à Odontologia pública no país. A indicação do ministro da Saúde, Ricardo Barros, de que será extinta a Coordenação- Geral de Saúde Bucal do Ministério da Saúde [...] Ficando órfã, a Odontologia Pública no Brasil ruma para a extinção ${ }^{\mathbf{2 3}}$.

A Federação Nacional dos Odontologistas (FNO) congrega, em sua base, 23 sindicatos, em todo território nacional tendo, portanto, representação nacional da categoria odontológica, vem a público informar que tomou conhecimento [...] que o Ministério da Saúde extinguiu a Coordenação Nacional de Saúde Bucal do Ministério da Saúde, responsável pela formulação e execução de uma política nacional para a saúde bucal, em benefício da população brasileira, primordialmente amparada pelo Sistema Único de Saúde (SUS) [...] Desde já manifestamos a rejeição a tal fato e informamos que encaminharemos expediente [...] solicitando a reversão da decisão de extinção da Coordenadoria Nacional da Saúde Bucal do Ministério da Saúde $\mathbf{2 4}$

O Conselho Federal de Odontologia vem, por meio de sua Comissão de Políticas Públicas de Saúde/Prêmio Brasil Sorridente, externar a preocupação de toda a classe odontológica diante das notícias de mudanças na Política Nacional de Saúde Bucal, com a exoneração de 73 cargos titulares e a possível extinção da coordenação do Ministério da Saúde. Acreditamos que é de suma importância a manutenção da referida coordenação para que a mesma possa exercer de forma independente, centralizada e interfederada, o papel de responsável pelas ações de saúde bucal no país. A sua extinção implicará em redução de investimentos no setor e consequente perda dos avanços conquistados pelo Brasil Sorridente. O momento da Odontologia brasileira pede avanços e não retrocessos. Não podemos tolerar o recuo nas conquistas recentes, não iremos admitir nenhum sorriso a menos ${ }^{22}$.
Em 5 de agosto de 2016, foi publicada a nomeação de Patrícia Lima Ferraz, CD, ligada ao Partido Social Cristão-Amapá, para o cargo de coordenadora da CGSB. A nomeação de Patrícia Ferraz, à época desconhecida pela maioria dos dentistas brasileiros, foi apontada pela FIO e pelo CFO como decorrente das manifestações das entidades de classe contra a extinção da CGSB. A sua permanência foi de cinco meses apenas, e sua saída do cargo ocorreu logo após situação polêmica, envolvendo uma viagem internacional enquanto estava de licença médica. Assim como os coordenadores dos últimos dois anos - Rozângela Camapum (2015) e Ademir Fatric (2016) -, o pouco tempo de permanência no cargo não evidenciou mudanças com relação aos componentes da PNSB.

No dia 06 de janeiro de 2017, o MS publicou a nomeação de Lívia Maria Almeida Coelho de Souza para o cargo de coordenadora. Lívia Souza é graduada em odontologia pela Universidade Federal do Pará, em 1999, especialista em Prótese Dentária e em Saúde da Família, foi consultora Unesco junto a CNSB durante dois anos e atuou no Programa de Saúde da Família no estado do Pará. Chama a atenção que foi organizadora, juntamente com Gilberto Pucca-Junior e outros autores, do 'Manual de Especialidades em Saúde Bucal', em 2008. Participou, também, como organizadora, de publicações importantes para a área, como os 'Cadernos de Atenção Básica', no 17, de saúde bucal, em 2008, bem como do próprio texto da política, publicado pela Organização Pan-Americana da Saúde (Opas) em português e inglês, intitulado 'A Política Nacional de Saúde Bucal do Brasil: registro de uma conquista histórica', em 2006. Ou seja, é uma agente do campo burocrático, que, de alguma forma, tem participado da formulação e implementação da atual política em curso.

Cabe relatar, também, o acontecimento da Assembleia Conjunta do CFO com os presidentes dos CROs, no mês de dezembro de 2016, em Brasília, a qual contou com a 
participação de lideranças da FNO e de vários sindicatos de CD. De acordo com o CFO, o objetivo do encontro foi somar as forças do Sistema CFO/CROs e de entidades sindicais em prol das causas da categoria odontológica. Nesse encontro, a FNO destacou como pleito o aumento do número de vagas para CD no SUS, considerando que a portaria que regulamenta as equipes de saúde da família não trata como prioritária a presença da equipe de saúde bucal. O CFO publicizou na matéria sobre a referida Assembleia que a reunião foi uma solicitação da FNO e da FIO ao CFO, que acatou o pedido. Esses fatos políticos evidenciam a relação entre esses agentes quando há interesses comuns da classe odontológica.

A entrada de Michel Temer, do Partido do Movimento Democrático do Brasil (PMDB), na presidência do País e as medidas que vêm sendo tomadas pela sua equipe revelam que o projeto de governo em vigor atualmente vai na direção contrária ao projeto de sociedade construído pelo movimento da Reforma Sanitária Brasileira, que deu origem ao SUS. A ocupação do cargo de ministro da Saúde por uma pessoa totalmente desvinculada da Saúde Coletiva é uma dessas evidências. $\mathrm{O}$ atual ministro Ricardo Barros, deputado federal licenciado (Partido Progressista Paraná), teve sua campanha financiada pela empresa Aliança (administradora de planos de saúde), e uma de suas afirmações mais polêmicas foi: 'é preciso reduzir o tamanho do SUS'25. Na sua gestão, foi criado um grupo de trabalho para compor uma proposta de 'Planos de Saúde Acessíveis'26. Diversos debates vêm sendo promovidos por segmentos dos movimentos sociais, do campo político e acadêmico. No caso da saúde, o foco principal tem sido as ameaças que as medidas do atual governo representam para o SUS e para os avanços e conquistas que esse sistema universal alcançou nos seus $\mathbf{2 8}$ anos de existência.

Por fim, importante destacar, ainda no ano de 2016, apresentação do projeto de lei pelo senador Humberto Costa (Partido dos Trabalhadores - PT-Pernambuco) e, em seguida, pelo deputado Jorge Solla (PTBahia), que transforma o programa Brasil Sorridente em política de Estado ${ }^{27,28}$. Essa é uma pauta antiga da odontologia brasileira, reforçada por suas entidades, que visa a garantir a permanência e o orçamento próprio da Política Nacional de Saúde Bucal, independentemente das mudanças de governo. As entidades odontológicas, CFO, FIO, ABO, e o ex-coordenador de Saúde Bucal, Gilberto Pucca, manifestaram apoio ao referido PL nas redes sociais.

\section{Ações e posicionamentos das enti- dades relacionadas com a PNSB, em 2017}

A FIO, nos primeiros meses do ano, deu grande enfoque sobre as reformas da previdência social e trabalhista. A terceirização na saúde também foi tema de debate. No dia 15 de março, a FIO participou de uma mobilização popular contra as reformas propostas e publicou em seu site uma nota de repúdio contra a aprovação, pela Câmara Federal, do Projeto de Lei $\mathrm{n}^{\circ} 4.302$, que libera a terceirização irrestrita da mão de obra no Brasil. No mesmo período, a FNO manifestou-se contra a proposta de criação do plano de saúde acessível que foi encaminhada à Agência Nacional de Saúde Suplementar (ANS) pelo MS. A entidade também se mobilizou contra a reforma da Previdência ${ }^{29}$.

AABO destacou sua participação no XXXV Congresso Internacional de Odontologia de São Paulo (Ciosp), evento de repercussão nacional que agrega diversas entidades odontológicas e vem mantendo espaço para discussão da PNSB em suas edições ${ }^{30}$. No mês de maio, a associação publicou inúmeras postagens em sua página no Facebook a respeito do projeto de lei que torna a política Brasil Sorridente uma lei federal, relatando sua aprovação, por unanimidade, pela Comissão de Assuntos Sociais do Senado. 
Em junho de 2017, a ABO publicou uma nota sobre uma pesquisa feita pelo MS, a qual apontou pouca acessibilidade de brasileiros a tratamentos odontológicos, afirmando que metade das pessoas com idade entre 35 e 45 anos já perdeu ao menos 12 dentes e que $80 \%$ dos idosos têm menos de 20 dentes na boca. Nessa mesma publicação, o presidente da entidade afirmou que essa realidade reforça a necessidade de transformar em lei federal o programa Brasil Sorridente ${ }^{31}$. Esse projeto de lei foi assunto destacado pelas entidades monitoradas ao longo do ano, e, no início de julho, o CFO publicou nota sobre o avanço no Congresso desse PL relatando a aprovação na Comissão de Assuntos Sociais do Senado e o encaminhamento para apreciação na Câmara dos Deputados. No mesmo dia, o CFO postou notícia sobre uma apresentação feita pela atual Coordenadora Nacional de Saúde Bucal (Lívia Maria Almeida) ao CFO e aos CROs, durante Assembleia Conjunta, em Brasília, onde apresentou em linhas gerais o seu trabalho na CNSB.

A FNO participou, em Brasília, da reunião do Fórum das Entidades Nacionais da Área da Saúde, evento que discutiu a defesa do SUS e desenvolveu ações para a construção de uma Política Nacional de Vigilância em Saúde. O CFO noticiou o lançamento da Frente Parlamentar da Odontologia, em Brasília, com a adesão de mais de 300 deputados. A autarquia publicou que essa Frente Parlamentar foi iniciativa da entidade em parceria com os conselhos regionais, com vistas a garantir mais recursos para as políticas de saúde bucal, além de defender os interesses dos $\mathrm{CD}^{32}$.

No cenário nacional, destaca-se um evento realizado no Planalto, em Brasília, para anúncio da liberação de R\$ 344,3 milhões para a saúde bucal. O evento teve participação do CFO e dos Conselhos Regionais, e, segundo nota divulgada pelo MS, a verba seria destinada à aquisição de 10 mil cadeiras odontológicas e 17 Unidades Odontológicas Móveis (UOMs) e para o custeio de 2.299 equipes de saúde bucal e 34 equipes de $\mathrm{UOMs}^{33}$. Outro fato político relevante foram as manifestações contrárias à publicação da nova Política Nacional de Atenção Básica (PNAB). No mês de agosto, CFO, ABO, FIO e FNO publicaram nota afirmando contrariedade sobre a revisão da PNAB. As entidades apontaram problemas que devem impactar consideravelmente a atenção básica, como a flexibilização da carga-horária dos profissionais, autonomia da gestão municipal na composição das equipes e a possibilidade de redução do número de Agentes Comunitários de Saúde (ACS) e dos Agentes de Combate às Endemias (ACE) ${ }^{34}$. A Abrasco, o Cebes e membros da Abrasbuco também manifestaram contrariedade à revisão da PNAB35.

Em setembro, a FIO publicou uma nota sobre o artigo de Paulo Capel Narvai, CD sanitarista, intitulado 'Infeliz decisão para o SUS'. O artigo é uma crítica à nova PNAB, que diz que a mudança não contempla reivindicações históricas dos profissionais, condena a possibilidade de contratação de profissionais de saúde para atuar na atenção básica, afirmando ser a oficialização da precarização do trabalho nesse nível de atenção, entre outras reivindicações. No dia seguinte, outro artigo de Paulo Capel foi citado no site da FIO, este de título ' $\mathrm{O}$ fim do Brasil Sorridente?', no qual Capel elenca decisões do governo que representam ameaças ao Brasil Sorridente. Por fim, ainda sobre a revisão da $\mathrm{PNAB}$, a FNO participou de uma reunião do Conselho Nacional de Saúde junto ao então ministro da saúde, Ricardo Barros, onde foi requerida a revogação da portaria da nova PNAB.

\section{Discussão}

No período 2015-2017, no Brasil, observaram-se diferentes níveis de engajamento das entidades odontológicas em torno da política de saúde bucal, com posicionamento mais crítico das entidades sindicais sobre a 
conjuntura política e econômica do período, bem como na reivindicação de demandas profissionais. Para melhor análise do papel das instituições na democracia participativa, é necessário compreender sua diversidade, suas especificidades e a natureza de cada uma delas ${ }^{36}$. Os sindicatos, historicamente, apresentam dificuldades para superar o padrão restrito de organização de interesses coorporativos no âmbito das lutas democráticas gerais, entretanto, o caso da Reforma Sanitária Brasileira foi uma experiência onde a participação dessas entidades contribuiu para ampliação das noções de justiça e equidade $^{37}$. Na Odontologia, as evidências do presente estudo apontam alguns avanços nesse aspecto, através da participação da FNO e da FIO em mesas de negociação e frentes de defesa do SUS para além da saúde bucal.

As relações com o campo político, bem como as ações de articulação e acompanhamento dos PL de interesse do campo odontológico, sobretudo por parte da FIO, FNO e CFO, expressam o potencial reivindicatório que essas instituições possuem junto ao campo político. Cabe destacar que os Projetos de Lei sobre piso salarial e plano de carreira no SUS, ao longo dessas últimas décadas, não avançaram na tramitação, e alguns foram arquivados, sendo essa uma pauta antiga de outras categorias profissionais de saúde e que envolve obstáculos, como o planejamento do sistema de saúde e processos de avaliação de desempenho, além do entendimento de que vai muito além da racionalidade administrativa, tendo um caráter também político, econômico, social e cultural ${ }^{38}$. De fato, a nova conformação do mercado de trabalho odontológico, em razão do grande contingente de profissionais, formados pelo número crescente de faculdades privadas a partir dos anos 2000 e do processo de expansão das empresas odontológicas de saúde suplementar, implicou o assalariamento de grande parte dos CD.

Lyra36 acredita que a participação de entidades da sociedade oxigena o Estado, proporciona mais transparência e o aproxima da população, todavia, não há consenso sobre as limitações 'genéticas', ligadas a uma representatividade limitada, considerando que essas instituições apresentam relações de organicidade com esse Estado, formulador e gestor das políticas sociais. Os conselhos profissionais são exemplos dessa organicidade, pois são dotados de direito público, apresentam poder de regulamentar e suspender licenças de atuação profissional, conferidas pelo próprio Estado ${ }^{39}$. A maior presença de publicações divulgando as ações e participações em eventos da CGSB e do próprio MS por parte do CFO é um achado que converge para essa natureza estatal dos conselhos, constituindo-se como braço do Estado no campo odontológico. Ou seja, confirmou-se a relativa influência do CFO na vocalização da política, sendo que o CFO se posiciona no sentido de apoiar o Estado na construção de uma agenda focada, principalmente, nos interesses da categoria em torno de novos empregos na área pública. Estudo de Rossi1 também apontou a presença dessa entidade nas negociações iniciais em torno do desenho da política e na 'costura' com o campo político-legislativo. O CFO exerce um papel muito mais de apoiador da política do que propositivo no que se refere aos seus conteúdos concretos. Rossi ${ }^{1}$ apresentou, ainda, a influência do CFO na saúde bucal desde a entrada na agenda até a sua formulação, em menor grau. $\mathrm{O}$ processo de definição de políticas públicas entre sociedade e Estado é complexo no mundo moderno, e a perspectiva do presente trabalho está mais próxima à posição teórica daqueles que defendem que existe um espaço da política com 'autonomia relativa do Estado', com forte presença de outros agentes e instituições fora do Estado. Esse estudo apontou o CFO no espaço da política de saúde bucal como instituição híbrida de posição dominante'. Esse aspecto se dá por a entidade representar o Estado $^{6} \mathrm{e}$ ser 'representante' dos CD. Por outro lado, verificou-se que a $\mathrm{ABO}$ não se constituiu em 
instituição dominante no espaço da política pública de saúde bucal nesse período, mas, sim, no espaço simbólico do campo odontológico, por ocupar a posição em defesa da odontologia 'liberal' e de mercado, que é dominante no habitus de classe.

$\mathrm{O}$ interesse fundamental da maioria das entidades recai sobre o 'crescimento' da odontologia, pela via de novos postos de trabalho no SUS, como é o caso da odontologia hospitalar em UTI. Chama a atenção que isso não ocorre no campo médico, já que estudo de Soares et al. ${ }^{2}$ observou reduzida preocupação das entidades médicas com a expansão da oferta de serviços públicos, principalmente na atenção primária, com grandes críticas à expansão do Programa Mais Médicos e também às propostas de mudança na formação médica, com 30\% do internato em serviços públicos, além da avaliação bianual, e, posteriormente, na formação massiva de especialistas, consideradas como propostas 'autoritárias', com grande tensão entre as entidades médicas e o governo no período 2015-2016². De acordo com o Conselho Federal de Medicina e com o Ministério da Educação, em 2018, há no País 452 mil médicos, 312 escolas de medicina, com $65,7 \%$ dos estudantes em faculdades privadas, enquanto na odontologia são mais de trezentos mil CD e cerca de 220 faculdades de Odontologia em funcionamento, com $75 \%$ delas da rede privada 7 . O provável motivo pode ter relação com a baixa oferta de médicos ainda no Brasil que não veem o serviço público e a atenção primária como postos de trabalho atrativos. Por outro lado, a ideologia liberal do campo médico é apontada e já observada nas origens da Reforma Sanitária Brasileira².

As sucessivas mudanças no MS e na CGSB bucal expressam a instabilidade política do período de 2015 a 2017, ocasionada sobretudo pela saída de Dilma Rousseff da presidência a partir de maio de 2016, através de um processo de impeachment, seguida pela entrada do vice-presidente Michel Temer.
Entre 2015 e 2017, foram nomeadas quatro pessoas diferentes para a coordenação da política de saúde bucal. Os estudos de Pinel140, na França, apontam a influência das mudanças de governo para manutenção ou abandono das políticas e do papel da emergência de grupos de agentes interessados na luta pela manutenção das conquistas, sendo, portanto, necessário seguir com o monitoramento das ações da atual gestão e seus efeitos concretos na implementação do Brasil Sorridente.

Outro papel dos representantes da sociedade é o de contribuir para avaliar o desempenho político e administrativo do gestor na implementação da política pública ${ }^{\mathbf{4 1}}$. Apesar das declarações de apoio e defesa dos serviços públicos odontológicos por todas as entidades, não foi encontrada nenhuma publicação específica de avaliação da política por parte delas.

As recentes medidas do Governo de Michel Temer na saúde - com destaque para a Emenda Constitucional de 2016, de ajuste fiscal, que congela os gastos sociais por 20 anos, a nova Política de Atenção Básica e a proposição de financiamento público para Planos de Saúde Acessíveis - foram repercutidas, criticadas e geraram ações e fatos políticos, como notas de repúdio e entrega de documentos ao governo pelas entidades monitoradas. Esses fatos configuram uma conjuntura de ameaça e ataques aos princípios de universalidade, igualdade e integralidade do SUS, conforme previstos na legislação brasileira, e reforçam a intenção dos atuais gestores de estreitar as relações com o setor privado e reduzir o papel do Estado na garantia e na oferta de serviços de saúde ${ }^{\mathbf{4 0 , 4 2}}$.

\section{Considerações finais}

As principais limitações do presente estudo se referem ao foco em um período limitado no tempo (2015-2017) e a não terem sido contempladas todas as instituições nacionais do campo odontológico interessadas na 
política de saúde bucal. Além disso, centrou-se na análise de dados secundários e não se aprofundou na trajetória dos agentes sociais que ocupavam cargo de direção dessas instituições nesse período. Essa é uma lacuna importante para novos estudos de abordagem sócio-histórica, na perspectiva Bourdiesiana ${ }^{5}$, a serem conduzidos, tendo se constituído numa exploração preliminar e parcial das principais categorias analíticas desse autor, como espaço social e campo.

A mudança de agentes sociais no MS, entre eles, a CGSB, reflete a saúde como moeda de troca no jogo político, entretanto, os impactos desses fatos ainda estão por vir e merecem acompanhamento. O presente estudo não pretendeu analisar a conjuntura política e econômica do Brasil em curso no período, entretanto, diante da dada crise, sobretudo política, o futuro do SUS e de todas as suas políticas é incerto, incluindo o Brasil Sorridente. Recomenda-se o acompanhamento das ações e dos posicionamentos das entidades odontológicas, considerando o potencial histórico desses agentes para influenciar o processo de implantação da PNSB e de outros projetos de interesse da saúde bucal coletiva brasileira.

As evidências deste trabalho reforçam a permanente articulação e o posicionamento comum das entidades odontológicas pela defesa de novos postos de trabalho no SUS para saúde bucal, com articulação importante com o campo político, através do legislativo, na aprovação de projetos de lei de interesse para esse espaço de luta, como a busca da transformação do Brasil Sorridente em política de Estado.

\section{Colaboradores}

Almeida AMFL participou da formulação da pesquisa, da coleta e análise dos dados, além da escrita e da revisão final do manuscrito. Chaves SCL coordenou a formulação da pesquisa, participou da análise dos dados e revisou o manuscrito final. Nunes LR e Araújo CO participaram da coleta e análise dos dados e da escrita do manuscrito final. 


\section{Referências}

1. Rossi TRA. Produção social das políticas de saúde no Brasil [tese]. Salvador: UFBA/ISC; 2016. 380 p.

2. Soares CM, Freitas MS, Teixeira CF, et al. Análise do posicionamento das Entidades Médicas: 2015-2016. Saúde debate [internet]. 2017 set [acesso em 2018 jul 11]; 41(esp.3):74-86. Disponível em: http://www. scielo.br/scielo.php?script=sci_arttext\&pid=S0103$-11042017000700074 \& \operatorname{lng}=$ pt.

3. Chaves SCL, Almeida AMFL, Santana SF, et al. A Política Nacional de Saúde Bucal no período 2003 a 2013: breves considerações sobre cenário e implementação [internet]. Salvador: Oaps; 2014 [acesso em 2018 jul 3] Disponível em: https://www.analisepoliticaemsaude.org/oaps/matriz/\#.

4. Silva FB, Jaccoud L, Beghin N. Políticas sociais no Brasil: participação social, conselhos e parcerias. In: Jaccoud L, organizador. Questão Social e Políticas Sociais no Brasil Contemporâneo. Brasília, DF: Ipea; 2005. p. 373-408.

5. Bourdieu P. Razões práticas: sobre a teoria da ação. 11. ed. Campinas: Papirus; 2011.

6. Bourdieu P. Sobre o Estado: Cursos no Collége de France (1989-92). 1. ed. São Paulo: Companhia das Letras; 2014.

7. Conselho Federal de Odontologia [internet]. Brasília, DF: CFO; c2018 [acesso em 2018 abr 20]. Disponível em: http://cfo.org.br.

8. Associação Brasileira de Odontologia. Notícias da Associação Brasileira de Odontologia [internet]. São Paulo: ABO; 2018 [acesso em 2018 abr 20]. Disponível em: http://abo.org.br/site/\#/home.

9. Federação Nacional dos Odontologistas [internet]. Brasília, DF: FNO; 2018 [acesso em 2018 abr 20]. Disponível em: http://www.fno.org.br.

10. Federação Interestadual dos Odontologistas [internet]. Brasília, DF: FIO; 2018 [acesso em 2018 abr
20]. Disponível em: http://www.fio.org.br/.

11. Associação Brasileira de Saúde Bucal Coletiva [internet]. São Paulo: Abrasbuco; c2003-2012 [acesso em 2015 abr 20]. Disponível em: http://abrasbuco. org/.

12. Conselho Federal de Odontologia. Valorização da Categoria [internet]. Brasília, DF: CFO; 2015 [acesso em 2015 ago 17]. Disponível em: http://cfo.org.br/ website/o-cfo-e-a-valorizacao-da-categoria/.

13. Conselho Federal de Odontologia. Campo Grande recebe o CFO no IV Encontro Sul Brasileiro de Saúde Bucal [internet]. Brasília, DF: CFO; 2015 [acesso em 2015 ago 28]. Disponível em: http://cfo.org.br/ website/campo-grande-recebe-o-cfo-no-iv-encontro-sul-brasileiro-de-saude-bucal/.

14. Conselho Federal de Odontologia. Natal (RN) vai sediar a V Reunião de Pesquisa em Saúde Bucal Coletiva [internet]. Brasília, DF: CFO; 2015 [acesso em 2015 set 29]. Disponível em: http://cfo.org.br/website/natal-rn-vai-sediar-a-v-reuniao-de-pesquisa-em-saude-bucal-coletiva/.

15. Conselho Federal de Odontologia. Ministério da Saúde tem nova Coordenadora de Saúde Bucal [internet]. Brasília, DF: CFO; 2015 [acesso em 2015 ago 24]. Disponível em: http://cfo.org.br/website/ ministerio-da-saude-tem-nova-coordenadora-de-saude-bucal/.

16. Conselho Regional de Odontologia de Goiás. Para onde vai o Brasil Sorridente: SUS ou mercado? [internet]. Goiânia: CROGO; 2015 [acesso em 2015 nov 22]. Disponível em: http://www.fio.org.br/index. $\mathrm{php} /$ noticias/destaques/381-para-onde-vai-o-brasilsorridente-sus-ou-mercado.

17. Associação Brasileira de Saúde Bucal Coletiva. Ofício enviado ao Ministério da Saúde [internet]. São Paulo: Abrasbuco; 2015 [acesso em 2015 nov 22]. Disponível em: http://www.abrasbuco.org/component/content/article/158.html. 
18. Confederação Nacional das Profissões Liberais. Federação Nacional dos Odontologistas apresenta propostas para a $15^{\text {a }}$ Conferência Nacional de Saúde [internet]. Brasília, DF: CNPL; 2015 [acesso em 2015 jun 12]. Disponível em: http://www.cnpl.org.br/ new/index.php/institucional/84-cnpl-brasil/675-federacao-nacional-dos-odontologistas-apresenta-propostas-para-a-15-conferencia-nacional-de-saude.

19. Federação Interestadual dos Odontologistas. Boletim Informativo - MNNP-SUS [internet]. Brasília, DF: FIO; c2017 [acesso em 2017 nov 17]. Disponível em: https://www.fio.org.br/index.php.

20. Associação Brasileira de Saúde Bucal Coletiva. Carta à Presidente Dilma Roussef e à sociedade: nota pública sobre o SUS e a Agenda Brasil [internet]. São Paulo: Abrasbuco; 2015 [acesso em 2017 nov 17]. Disponível em: http://www.abrasbuco.org/component/content/article/89-home-abr-2015/157-carta-a-presidente-dilma-roussef-e-a-sociedade-nota-publica-sobre-o-sus-e-a-qagenda-brasilq.html.

21. Conselho Federal de Odontologia. Coordenador Nacional de Saúde Bucal do Ministério da Saúde visita CFO [internet]. Brasília, DF: CFO; 2016 [acesso em 2018 abr 30]. Disponível em: http://cfo.org. br/website/coordenador-nacional-de-saude-bucal-do-ministerio-da-saude-visita-cfo/.

22. Conselho Federal de Odontologia. Nota Oficial sobre possível extinção da Coordenação Nacional de Saúde Bucal [internet]. Brasília, DF: CFO; c2015 [acesso em 2016 ago 8]. Disponível em: http://www. cro-rj.org.br/cfo-condena-possivel-extincao-da-coordenacao-nacional-de-saude-bucal/.

23. Federação interestadual dos Odontologistas. Nota de repúdio [internet]. 2016. [acesso em 2016 out 15]. Disponível em: https://www.facebook. com/610696648962828/photos/a.62813230055259 6/1241145125917974/?type=3\&theater.

24. Federação Nacional dos Odontologistas. Nota Pública [internet]. Brasília, DF: CFO; 2016 [acesso em 2016 ago 30]. Disponível em: http://lookinformati- ca.com/wp/index.php/2016/08/01/nota-publica/.

25. Colussi C. Tamanho do SUS precisa ser revisto, diz novo ministro da Saúde [internet]. Folha de S. Paulo 2016 maio 17 [acesso em 2016 maio 17]. Disponível em: https://wwwl.folha.uol.com.br/ cotidiano/2016/05/1771901-tamanho-do-sus-precisa-ser-revisto-diz-novo-ministro-da-saude.shtml.

26. Brasil. Ministério de Saúde. Portaria $n^{\circ} 1.482$, de 04 de agosto de 2016. Institui Grupo de Trabalho para discutir projeto de Plano de Saúde Acessível. Diário Oficial da União. 4 Ago 2016. Disponível em: http:// bvsms.saude.gov.br/bvs/saudelegis/gm/2016/ prt1482_04_08_2016.html.

27. Câmara dos Deputados. Projeto de Lei 6836/2017. Dispõe sobre a Política Nacional de Saúde Bucal no âmbito do Sistema Único de Saúde (SUS) e altera a Lei no 8.080, de 19 de setembro de 1990, para incluir a saúde bucal no campo de atuação do SUS. Diário Oficial da União. 7 Fev 2017. Disponível em http:// www.camara.gov.br/proposicoesWeb/fichadetrami tacao?idProposicao=2122955.

28. Senado Federal. Projeto de Lei do Senado (PLS) 8/2017. Inclui o programa de saúde bucal Brasil Sorridente no Sistema Único de Saúde (SUS). Diário Oficial da União. Disponível em: https://www12.senado.leg.br/noticias/materias/2017/07/05/politica-nacional-de-saude-bucal-pode-ser-oficialmente-incluida-no-sus.

29. Campos Sobrinho JF. Odontologistas reforçam mobilização de 18 de abril [internet]. Brasília, DF: CNTU; 2017 [acesso em 2017 abr 13]. Disponível em: http://www.cntu.org.br/new/noticias-lista/4543-odontologistas-reforcam-mobilizacao-de-28-de-abril.

30. Associação Brasileira de Odontologia. Solenidade marca abertura do $35^{\circ}$ CIOSP [internet]. Brasília, DF: ABO; 2017 [acesso em 2017 mar 16]. Disponível em: http://www.abo.org.br/noticia/solenidade-marca-abertura-do-35-ciosp.

31. Associação Brasileira de Odontologia. Pesquisa 
aponta pouca acessibilidade de brasileiros a tratamentos odontológicos [internet]. Brasília, DF: ABO; 2017 [acesso em 2017 jun 9]. Disponível em: http:// www.abo.org.br/site/2017/06/07/pesquisa-aponta-poucaacessibilidade-de-brasileiros-a-tratamentos-odontologicos.

32. Conselho Federal de Odontologia. Criação de Frente Parlamentar da Odontologia [internet]. Brasília, DF: CFO; 2017 [acesso em 2017 out 24]. Disponível em: http://cfo.org.br/website/com-mais-de-300-assinaturas-frente-parlamentar-da-odontologia-e-criada-no-congresso/.

33. Conselho Federal de Odontologia. CFO e CROs participam do anúncio da liberação de $\mathrm{R} \$ 344,3 \mathrm{mi}-$ lhões para saúde bucal [internet]. Brasília, DF: CFO; 2017. Disponível em: http://cfo.org.br/website/cfo-e-cros-participam-do-anuncio-da-liberacao-de-r-3443-milhoes-para-saude-bucal/.

34. Conselho Federal de Odontologia. Posicionamento do CFO sobre a revisão da Política Nacional de Atenção Básica [internet]. Brasília, DF: CFO; 2017 [acesso em 2017 ago 10]. Disponível em: http://cfo. org.br/website/posicionamento-do-cfo-sobre-a-revisao-da-politica-nacional-de-atencao-basica/.

35. Centro Brasileiro de Estudos de Saúde. Contra a reformulação da PNAB - nota sobre a revisão da Política Nacional de Atenção Básica [internet]. Rio de Janeiro: Cebes; 2017 [acesso em 2017 jul 27]. Disponível em: http://cebes.org.br/2017/07/contra-a-reformulacao-da-pnab-nota-sobre-a-revisao-da-politica-nacional-de-atencao-basica/.

36. Lyra RP. Democracia representativa $\mathrm{x}$ democracia participativa: a representação do estado e da sociedade civil nos conselhos de políticas públicas. In: Anais do II Seminário Nacional sobre Movimentos Sociais, Participação e Democracia; 2007. Florianópolis: UFSC; 2007.
37. Costa NR. Políticas públicas, direitos e interesses: reforma sanitária e organização sindical no Brasil. Rev Adm Pública [internet]. 1994 [acesso em 2018 jun 20]; 28(4):5-7. Disponível em: http://bibliotecadigital.fgv.br/ojs/index.php/rap/article/viewFile/8313/7088.

38. Vieira SV, Pierantoni CR, Magnago C, et al. Planos de carreira, cargos e salários no âmbito do Sistema Único de Saúde: além dos limites e testando possibilidades. Saúde debate [internet]. 2017 [acesso em 2018 jun 20]; 41(112):110-121. Disponível em: http:// www.scielo.br/pdf/sdeb/v41n112/0103-1104sdeb-41-112-0110.pdf.

39. Costa BRM, Valente MAL. Responsabilidade Social dos Conselhos Profissionais. Consultoria Legislativa [internet]. 2008 nov [acesso 2018 jun 20]; 1-13. Disponível em: http://www2.camara.leg.br/a-camara/documentos-e-pesquisa/estudos-e-notas-tecnicas/areas-da-conle/temal/2008-14144.pdf.

40. Pinell P. Análise sociológica das políticas de saúde. In: Pinell P. Algumas reflexões sobre as políticas de luta contra os flagelos sociais. Rio de Janeiro: Fiocruz; 2010. p. 229-250.

41. Silva MJS, Silva MD, Silva AX. O processo de contrarreforma na política de saúde. In: Anais da VIII Jornada Internacional de Políticas Públicas; 2017 ago 22-25. Maranhão: UFMA; 2017. p. 1-12.

42. Morosini MVG, Fonseca AF. Revisão da Política Nacional de Atenção Básica numa hora dessas. Cad Saúde Pública. 2017; 33(1):1-4.

Recebido em 14/07/2018

Aprovado em 19/09/2018

Conflito de interesses: inexistente

Suporte financeiro: não houve 